\title{
Long Average Unemployment Duration Implies Better Job Market
}

\author{
Peter L. D'Antonio, Ph.D. \\ Molloy College \\ School of Business \\ 1000 Hempstead Avenue \\ Rockville Centre, NY 11571 \\ USA
}

\begin{abstract}
Long-term unemployment was one of the biggest problems during the Great Recession. Nearly half of all unemployed persons were out of work for six months or more. Since then, the average duration of unemployment has gradually diminished along with the unemployment rate, but it has nevertheless remained relatively long. In fact, the average duration is still longer than every prior post-WWII recession. Along average duration of unemployment has traditionally indicated structural impediments in the labor market, such as skills mismatches. Therefore, the current long average duration is naturally seen as a sign of continued weakness. In contrast, this paper posits that the elevated duration of unemployment actually indicates an unusually well-functioning labor market. The long duration of unemployment isthe result of very short job searches for newly unemployed workers and is unrelated to long-term unemployment. Consequently, policies designed to solve this "problem" may be unnecessary and misguided.
\end{abstract}

Keywords: average unemployment duration, structural unemployment, job mismatches

\section{Developments since the Great Recession}

The sharp rise in the duration of unemployment was a major focus of policy during the Great Recession and the subsequent slow recovery. Former Fed Chair Ben Bernanke (2012) argued that the predominant force driving average duration of unemployment higher was cyclical, and therefore accommodative policies should alleviate the problem. Later, former Fed Chair, Janet Yellen (2014) highlighted alternative sources of labor market slack, including the "large share of the unemployed who have been out of work for six months or more." She said, "These workers find it exceptionally hard to find steady, regular work, and they appear to be at a severe competitive disadvantage when trying to find a job."Yellen leveraged these alternative sources of slack to justify continued extraordinary monetary policy stimulus, even as the unemployment rate declined.

A Congressional Budget Office study (Carrington, 2014) attributed the long duration of unemployment to four forces: weak demand, generous unemployment insurance benefits, mismatches between worker skills and job requirements, and the loss of job skills during periods of unemployment. The first force (weak demand)is cyclical, and the last three forces are structural.

Two of these forces have been eliminated in recent years - weak demand and extended unemployment insurance. Weak demand generated cyclical unemployment. However, now that the unemployment rate has fallen well below Federal Reserve policymakers' assessment of the natural rate of unemployment, or the long-term unemployment rate (FOMC Statement, 2019 and BLS, 2019, 3), there is no cyclical reason for the elevated duration of unemployment. ${ }^{1}$ Also, unemployment insurance was scaled back to more normal levels by the end of 2013 (ATRA, 2012).

As a result, most analysts have concluded that the continued long average duration is evidence that the other two structural forces (skill mismatches and job skill losses) must be hampering the labor market. For instance, a Century Foundation study (McCormack, 2017) says the "hidden story is the unprecedented levels of long-term unemployment." McCormack claims that "long-term unemployment has remained stubbornly high" and attributes it to a "hangover from the Great Recession and a demonstration of how hard it continues to be to find work." The elevated average duration has kept this idea in the public eye. For example, Jericho (2018) says that "long-term unemployment has become an increasing concern." Lanman (2019) claims that the high share of long-term unemployed is a sign that there is still slack in the labor market.

\footnotetext{
${ }^{1}$ Haver Analytics provided all the economic data in this study.
} 
Even economists at the Federal Reserve Bank of St. Louis have indicated that the elevated duration of unemployment signals labor market weakness (St. Louis Fed, 2018). It is a very powerful statement when the Fed gives its imprimatur to an idea like this. In a recent blog post entitled "The Unusual Duration of Unemployment: The Scars of the Great Recession," St. Louis Fed economists contrast an improving unemployment rate with a stubbornly high average duration of unemployment (see Chart 1). St. Louis Fed researchers state that:

"The share of long-term unemployment is significantly higher than in any other post-WWII period. Indeed, those unemployed for more than six months still represent 20 percent of the unemployed, after a peak of over 45 percent in 2011. The share increases after recessions, but the most recent recession was deeper and much longer than the others. It's also well-known that the long-term unemployed have a much harder time finding a job [...] And thus their numbers still persist at a high level" (St. Louis Fed, 2018).

The St. Louis Fed economists and other analysts are essentially attributing the current long average duration of unemployment to a combination of the Great Recession legacy and the difficulty that the long-term unemployed generally experience landing jobs. By implication, if the labor market is still hobbled in this way, there may be reason to continue policies designed to alleviate the pain associated with long-term unemployment, such as accommodative monetary and fiscal policies, job training and search assistance, tax credits, and reduced payroll taxes (CBO, 2014).

However, neither of these factors - the Great Recession legacy nor the difficulties long-term unemployed have finding jobs - actually explains the current long average duration of unemployment. The elevated average duration figure no longer reflects an abundance of long-term unemployed, as was the case during the Great Recession and the immediate aftermath. Instead, the elevated duration can be attributed to how few short-term unemployed there are in the labor market now.

\section{Benchmarking the long-term unemployment pool}

The St. Louis Fed researchers are absolutely correct that the share of people out of work for six months or more remains nearly as high as at the height of the worst previous post-WWII recessions (St. Louis Fed, 2018). Currently, 20 percent of unemployed workers are out of work for a half year or more, and 8 percent have been out of work for a year or more (BLS, 2019, 3). In 1982when the economy was near the trough of a harsh recession, about 25 percent of unemployed workers were out of work for a half year or more. The difference is that the current high duration of unemployment follows an economic expansion of ten years and the unemployment rate is unusually low. As the St. Louis Fed blog title - The Scars of the Great Recession - suggests, this elevated share of long-term unemployed is seen as a sign of hidden distress in the labor market.

Unemployment shares can be misleading, however. Duration of unemployment data are published as levels and as shares of unemployment (BLS, 2019, 2) and, as the previous examples show, it has become customary to look at them by shares. But the raw numbers of unemployed workers by duration tell a vastly different story than the shares. The raw numbers of unemployed people out of work for more than a half year or a full year are actually quite low, both in absolute terms and relative to the size of the labor force. There are currently just 1.3 million people unemployed for more than a half year and about 500, 000 for more than a year. In contrast, these figures reached 7.0 million and 3.6 million respectively in the last recession. The current levels of long-term unemployment are on par with the lowest readings of the previous expansion (BLS, 2019, 2). Meanwhile, the labor force has grown significantly in the past eleven years since the last expansion, suggesting that the current long-term unemployment figure may be even less worrisome when benchmarked against the entire labor force.

The published shares of unemployment by duration are stated as a percent of the total number of unemployed workers. For instance, the data take the long-term unemployed as a share of the total number of unemployed. This choice of benchmark, however, can make it difficult to assess the health of the labor force. The total number of unemployed changes dramatically through the business cycle. It is far different to say that 45 percent of the unemployed are out of work for a half year or more when the unemployment rate is 10 percent than when the unemployment rate is 3.7 percent. How can we get a benchmark that indicates the overall prevalence of long-term unemployment in the labor market?

Taking the ratio of long-term unemployed to the overall labor force, essentially deriving a long-term unemployment rate, can give a better sense of the prevalence of long-term unemployment. Chart2 shows that this long-term unemployment rate is currently near the lowest level on record (for both six- and twelve-month spans). In other words, given the size of the labor market, there actually are relatively few people experiencing bouts of long-term unemployment. There does not appear to be an added layer of stress in the labor market that is being picked up by the high average duration of unemployment. Consequently, the high average duration should not be used to advocate for extraordinary policies to mitigate any implied lurking weakness. 


\section{Few Newly Unemployed and Short Searches}

So how can two statistics - the elevated share of long-term unemployed and the high average duration of unemployment - suggest continued troubles in the labor market, while at the same time this long-term unemployment rate statistic signals an extremely healthy labor market? The answer lies in what has happened to short-term unemployment during this expansion and over the past three decades.

The average duration of unemployment is calculated as a weighted average of the number of weeks unemployed times the number of people at each level of weeks. The equation is written

Average Duration $=\sum \mathrm{N}_{\mathrm{i}} \cdot \mathrm{W}_{\mathrm{i}} / \sum \mathrm{N}_{\mathrm{i}}$

where $\mathrm{N}_{\mathrm{i}}$ is the number of unemployed people and $\mathrm{W}_{\mathrm{i}}$ is the number of weeks they have been unemployed (Corak and Heisz, 1996).

The average can be high for two reasons. The natural thought is a high average duration of unemployment would be caused by an elevated number of people who are unemployed for long periods. However, the average can also be high because there is a low number unemployed for short periods.

The number of short-term unemployed people - the newly unemployed-is extremely low by historical standards. The proportion of the labor force that is out of work for a month or less - the short-term unemployment rate -is currently at just 1.3 percent. That is the lowest proportion of the labor force since the BLS started collecting the data in 1948(BLS, 2019, 2). In fact, there has been a steady decline in short-term unemployment since the 1980s (see Chart3).

Meanwhile, long-term unemployment has shown a clear cyclical pattern, with the latest recession experiencing a massive spike. However, Chart3also shows that the calculated long-term unemployment rate has been remarkably consistent as expansions have reached full employment. Currently, the unemployment rate for people out of work six months or more is 0.8 percent, which is within a half point of each of the previous five cycle lows. So, controlling for the state of the business cycle (i.e., looking only at the periods when the economy was at full employment), the real shift in the pattern of unemployment duration has been entirely in short-duration unemployment.

Moreover, newly unemployed people generally find jobs very quickly. In fact, most job searches last less than two months. Using BLS unpublished labor force flows data(BLS, 2019, 3), the probability of a newly unemployed person remaining unemployed after five weeks can be calculated in a manner similar to the "continuation rates" of Corak and Heisz (1996).Currently, there is a 38 percent probability that a person will remain unemployed. In other words, there is over a 60 percent chance that a newly unemployed person will either find employment or leave the workforce within two months (40 percent chance of finding a new job and 22 percent chance of leaving the workforce). ${ }^{2}$ Even during the worst of the Great Recession, the probability of remaining unemployed for more than a month hovered near 50 percent. Given the relatively low number of newly unemployed people and the relative speed with which the short-term unemployed find jobs, it is no wonder that unemployment is skewed toward a longer average duration.In fact, the number of short-term unemployed is so low that it has boosted the average duration even though there is a low number of long-term unemployed.

\section{Sign of strength}

While it may seem counterintuitive, the elevated average duration of unemployment really is a sign that the labor market is doing very well. This can be seen by imagining that the calculated short-term unemployment rate did not decline over the past few decades. Let's say that the number of short-term unemployed represented about 2.3 percent of the labor force (on par with the lowest points of the previous two expansions). All else equal, the economy would not be as well off as it is today with only 1.3 percent of the labor force unemployed for a short duration.

How would the statistics change if this were the case? The overall unemployment rate would obviously be higher. Leaving the number of people unemployed constant for all longer tranches of duration, while raising the number of short-term unemployed, would have to raise the overall unemployment rate. It turns out that the increase in short-term unemployment rate from 1.3 percent to 2.3 percent would raise the overall by unemployment rate by a point as well from 3.7 percent to 4.7 percent. $^{3}$

\footnotetext{
${ }^{2}$ The labor force status flows data can give probabilities of finding a new job or leaving the workforce. The probability of remaining unemployed is based on the ratio of the number of people unemployed for less than five weeks who remained unemployed to the total number unemployed less than five weeks the month before. The probabilities in this report follow the work in D'Antonio (2014).

${ }^{3}$ The sum of the unemployment rates by duration equals the overall unemployment rate. So, increasing any one of the duration tranche unemployment rates will cause the total to rise by the same amount. In this case, the 1 percentage point increase in the short-term unemployment rate boosts the total by 1 percentage point, to 4.7 percent.
} 
What would happen to the average duration of unemployment if the short-term unemployment rate were a point higher? There would be more weight on the shorter end of the duration spectrum, pulling the average down. The increase in the unemployment rate would at the same time cause the average duration of unemployment to decline by three and a half months to 16.7 months. ${ }^{4}$ An average duration of unemployment in that range would not be considered problematic, as it would be near the lows of the previous expansion (see Chart 1). In other words, a more normal number of people unemployed for short periods, relative to the size of the labor force, would signal a less robust labor market, but would be consistent with a sharply lower average duration of unemployment.

\section{Conclusion}

This analysis shows that the elevated level of the duration of unemployment is not a sign of hidden slack in the labor market. The extremely low unemployment rate, along with the low incidence of long-term unemployment, implies that the labor market is currently operating at a point beyond full employment, notwithstanding the high average duration reading. In fact, the duration figure appears to be a statistical artifact of the strength and efficiency evident in the low short-term unemployment rate. As a result, it would be misguided to conduct policy to address the long-term unemployment "problem" when the labor market is actually functioning extremely well.

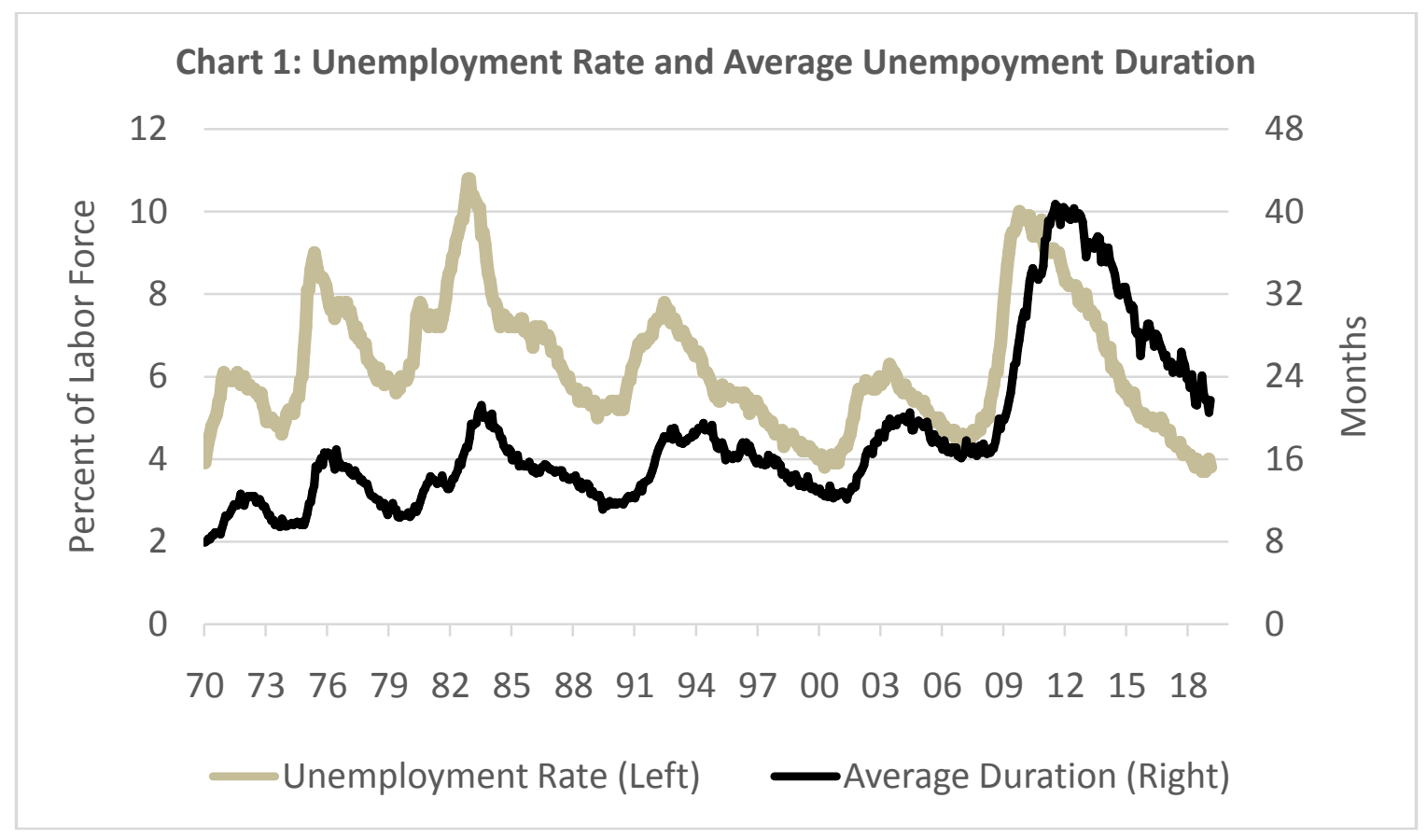

Source: Bureau of Labor Statistics.

\footnotetext{
${ }^{4}$ For the short-term unemployment rate to increase by 1 percentage point, there would have to be about 1.6 million more people unemployed for 0 to 5 weeks. In that case, theaverage duration of unemployment calculation would be more heavily weighted toward the shortest duration.
} 


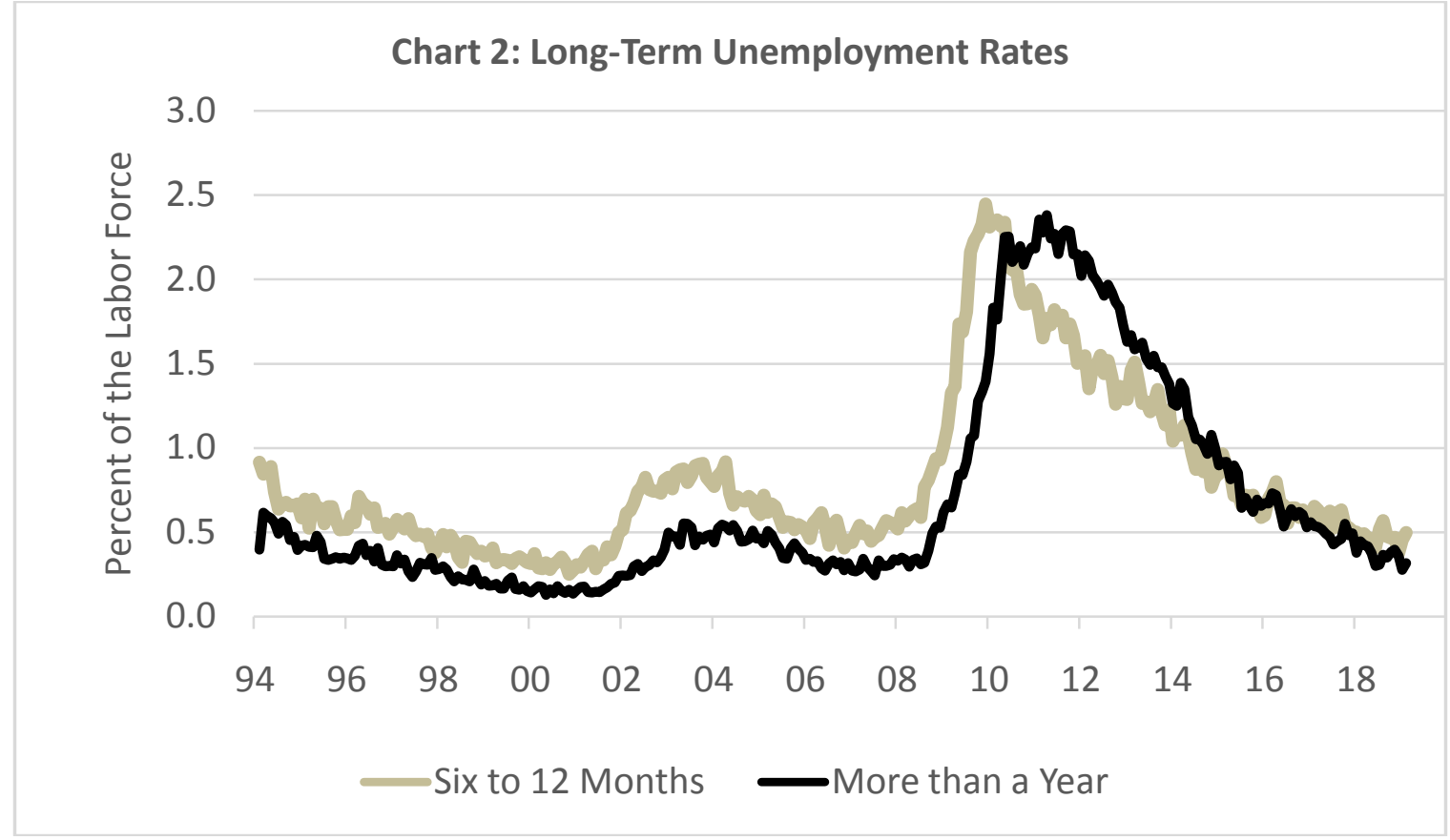

Source: Bureau of Labor Statistics.

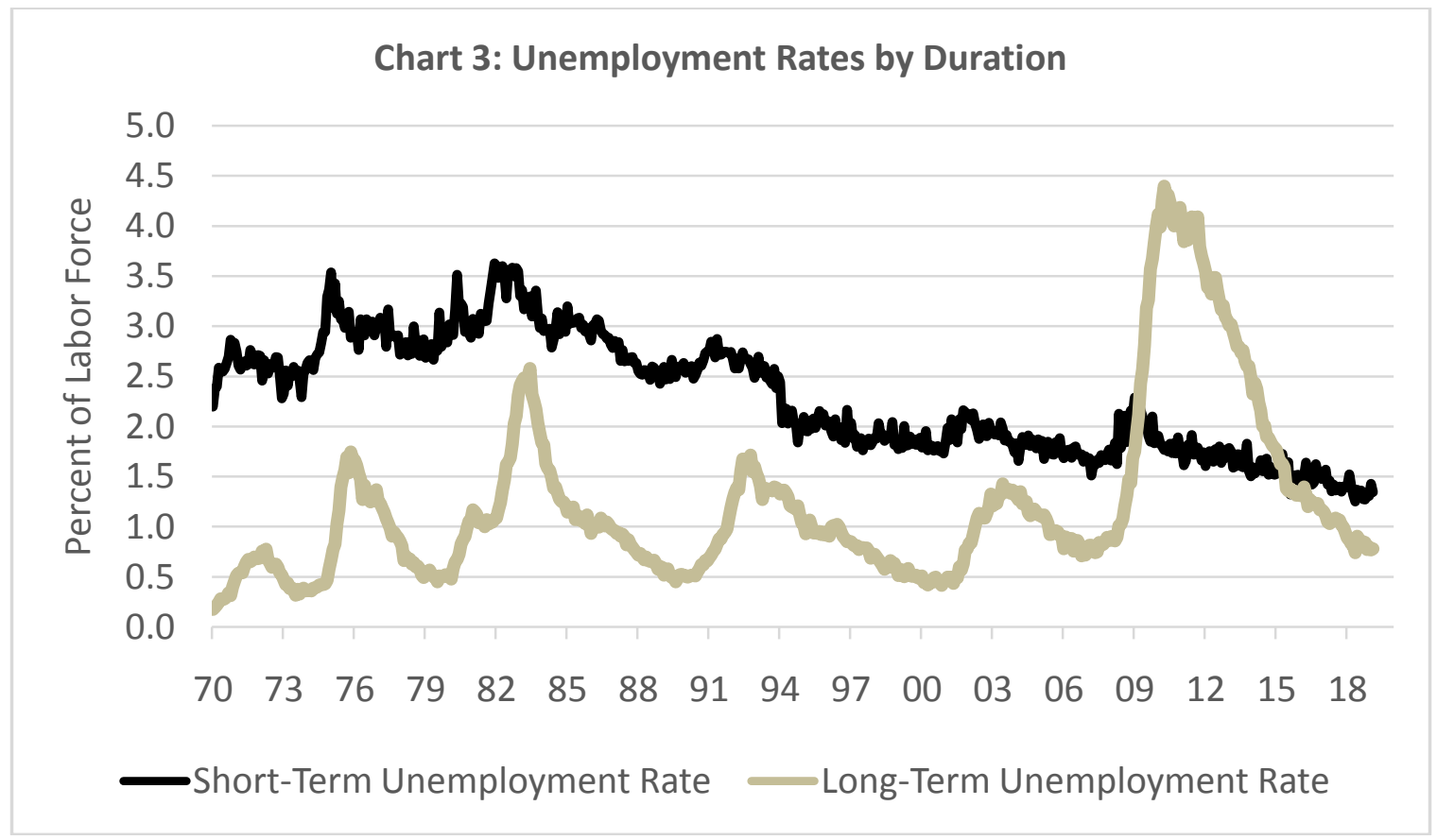

Source: Bureau of Labor Statistics.

\section{References}

American Taxpayer Relief Act of 2012. H.R.8, 112th Congress. Public Law No: 112-240. July 24, 2012.

Bernanke, B. S. (2012). Recent Developments in the Labor Market. Federal Reserve Board. Speech at the National Association for Business Economics Annual Conference, Washington, DC. March 26, 2012.

Bureau of Labor Statistics (2018, 1). Employment Situation: Household Survey, Table A-1 Employment Status of the Civilian Population by Sex and Age. Updated March 8, 2019. 
Bureau of Labor Statistics (2018, 2). Employment Situation: Household Survey, Table A-12 Duration of Unemployment. Updated March 8, 2019.

Bureau of Labor Statistics $(2018,3)$. Labor Force Status Flows by Duration of Unemployment, Unpublished Research Series. Updated March 8, 2019.

Carrington, W. J. (2014). The Rise in Long-Term Unemployment: Causes, Effects and Policy Options. Congressional Budget Office. Presentation to the Winter Policy Forum of the National Association of State Workforce Agencies. February 20, 2014.

Corak, M. \&Heisz, A. (1996). Alternative Measures of the Average Duration of Unemployment. Statistics Canada. Review of Income and Wealth, Series 42, Number 1. March 1996.

D’Antonio, P. L. (2014). 'Unlucky' Job Searches. Market and Policy Comments. Citi Research. May 23, 2014.

Federal Reserve Bank of St. Louis (2018). The Unusual Duration of Unemployment: The Scars of the Great Recession, Blog Post. November 8, 2018.

Haver Analytics, Inc. provided all the economic data for this study.

Jericho, G. (2018). Long-Term Unemployment Rate Shows Jobs Picture Is Not So Rosy. The Guardian. August 27, 2018.

Lanman, S. (2019). Best US Job Numbers Ever? Not If You're Out of Work for a Year. Bloomberg, Economics. February 12, 2019.

McCormack, M. (2017). Despite Continued Job Growth, Long-Term Unemployment Persists. Century Foundation, Commentary. August 4, 2017.

Statement of Economic Projections (2019). Federal Open Market Committee, Table 1. March 20, 2019.

Yellen, J. L. (2014). What the Federal Reserve Is Doing to Promote a Stronger Job Market. Federal Reserve Board. Speech at the 2014 National Interagency Community Reinvestment Conference, Chicago, IL. March 31, 2014. 